\title{
A Normative Yet COHERENT NATURALISM
}

\author{
Steve Petersen
}

\begin{abstract}
Naturalism is normally taken to be an ideology, censuring nonnaturalistic alternatives. But as many critics have pointed out, this ideological stance looks internally incoherent, since it is not obviously endorsed by naturalistic methods. Naturalists who have addressed this problem universally foreswear the normative component of naturalism by, in effect, giving up science's exclusive claim to legitimacy. This option makes naturalism into an empty expression of personal preference that can carry no weight in the philosophical or political spheres. In response to this dilemma, I argue that on a popular (but largely unarticulated) construal of naturalism as a commitment to inference to the best explanation, methodological naturalism can be both normative and internally coherent.
\end{abstract}

Philosophical naturalism faces a difficult but often neglected dilemma: take it as a normative position and it risks internal incoherence, since such an ideological stance itself cannot be a deliverance of science. Forgo the evaluative aspect, on the other hand, and naturalism becomes a merely subjective assessment, a cry of "yay for science!" that carries no normative weight for those who are not inclined to agree.

I first argue that both horns of this dilemma are sharp and that current attempts to negotiate them have failed. I then give a plausible construal of methodological naturalism that is both normative and internally coherent, and so threads this dilemma. Finally, I respond to objections against this formulation of naturalism, and consider the dialectical position in which it leaves us. Though the resulting naturalism cannot (of course) convince dedicated nonnaturalists who will insist on other belief-forming methods, it does at least provide a pragmatic advantage when debating the relative advantages of such methodologies.

Steve Petersen, Niagara University, Lewiston, New York 


\section{The Dilemma}

When at all ambitious, naturalism is both a philosophical and a political movement. It is an ideology - a way of doing things that scorns alternatives in the same way that other isms such as capitalism and communism do. Many (probably most) professional analytic philosophers are on board with this movement, and would classify themselves as naturalists. ${ }^{1}$ An accusation of nonnaturalism would hold force with them, and make them reconsider their views. Meanwhile, in the political sphere, organizations such as the Center for Inquiry, The Brights, and the Center for Naturalism raise money and seek to influence public policy in its name. They fight, for example, having nonnaturalistic views taught in public schools. And yet this very ideological stance threatens to make such ambitious naturalism self-undermining.

\subsection{The INCOHERENGE HoRN}

To see the first horn of the dilemma, one need only recall this philosophical chestnut from the heyday of logical positivism:

Simple Verificationist: The meaning of a proposition is fully determined by the observable tests for the truth or falsity of that proposition.

SMARTYPANTS: Oh? And what is the meaning of that proposition?

Naturalists who cannot remember this past are in danger of repeating it. Consider, for example, this dialogue with an ambitious methodological naturalist, who is committed to the procedures of science:

Simple Naturalist: Science is the only source of knowledge.

SMARTYPANTS: Oh? And by what scientific methodology did you obtain that knowledge?

The first of these was problematic for verificationism, and the version for naturalism looks disturbingly analogous.

Variations on this argument have been popping up in the literature. Paul Moser and David Yandell, in their attack on naturalism, put it this way:

[Ambitious naturalism] is not itself a thesis offered by any empirical science. In particular, neither its ontological component nor its methodological component is a thesis of an empirical science. Neither component is represented in the empirical scientific work of either physics, chemistry, biology, anthropology, psychology, or any other natural or social empirical science. As a result, no research fundable by the National Science Foundation, for instance, offers [ambitious naturalism] as a scientific thesis. In contrast, the National Endowment for the Humanities would fund work centered on [ambitious naturalism]. ${ }^{2}$

William Alston puts it this way:

... on any halfway plausible way of drawing boundaries around "scientific method," the proposal to do epistemology only by scientific method would put virtually all actual epistemologists out of business—Quine included. ${ }^{3}$

Robert Almeder, in his attack on ambitious versions of naturalism (on the way 
toward a "harmless" naturalism to replace it), puts it this way:

... Quine's argument for [ambitious naturalism] is a philosophical argument whose general conclusion, whatever the premises, is not properly testable under the methods of natural science. Indeed, as an hypothesis, Quine's conclusion that there are no correct answers or statements that either have emerged, or can emerge, from extra-scientific methods (that is, that there is no "first philosophy") has no statable sensory test implications that would allow us to confirm it positively. ${ }^{4}$

Almeder credits Harvey Siegel with the first statement of this argument, and he also cites instances in Laurence BonJour, Nicholas Rescher, Alex Rosenberg, and Paul Sagal. ${ }^{5}$ Almeder says that this argument from incoherence is "as solid a refutation of the position as one could possibly imagine" and that "nobody who adopts [ambitious naturalism] has yet confronted the argument seriously." By now, the general shape of this objection is clear.

As hinted above, a naturalistic stance must be minimally "ambitious," in a certain sense, in order to be susceptible to this objection. Moser and Yandell, for example, say their argument targets any naturalism with a "monopolistic posture."7 Marc Alspector-Kelly, in an unpublished response to the incoherence objection, says any naturalism with an "exclusionary clause" will fall prey. ${ }^{8}$ Almeder says his version of naturalism escapes the dilemma for being "less imperialistic." All these suggestions point to the same thing: naturalism gets in trouble with internal coherence when it becomes "fraught with ought" - when it evaluates alternatives as bad and thereby takes a distinctively normative cast. The examples above focus on the methodological naturalist who has the chutzpah to say we should pursue only the method of science (for some important realm), but the ontological naturalist is in just as much trouble if she says we should not grant existence to what is not countenanced by science. We expect a science lab to find scientific entities, but we would be surprised if the same lab published a result to the effect that only the scientific entities exist.

\subsection{The Tolerance Horn}

Naturalists who have considered this objection have all responded in essentially the same way: by giving up the ambition. We should think of naturalism as basically a pro-science position, they say, and not burden it with any particularly philosophical attempt to rule out competitors. Alspector-Kelly, for example, suggests instead an "opportunistic" naturalism that seeks to explain as much as possible naturalistically without insisting along the way that nonnaturalists must be on the wrong track. ${ }^{10}$ Penelope Maddy has drifted toward a similar position with her "second philosophy" formulation of naturalism; she says of her second philosopher that "nowhere does she repudiate, on principle, any inquiry or method." 11 Almeder's "harmless naturalism" concedes that "some legitimately answerable questions about human knowledge and the world are not answerable by appeal to the methods of the natural science."12

This all sounds admirably pluralistic, at least in the abstract. But to give up the exclusionary clause is to give up naturalism's normativity-at least, 
its most interesting component-and this is no small concession. It is automatically to countenance a permissive attitude toward nonnaturalistic entities or methods of exactly the type that motivate people to champion naturalism in the first place. If tolerant naturalism were widely adopted in the political sphere, for example, the political organizations mentioned previously would have to abandon their efforts to exclude nonnaturalistic elements from public policy. Though the tolerant naturalists prefer the scientific approaches themselves, they view this as a mere preference; they cannot condemn the nonscientific. If others want to spend precious tax money or university resources on non-naturalistic enterprises, then let a hundred flowers blossom! Of course, the tolerant naturalists might say they would resist each nonscientific proposal on different grounds. To make any kind of general case for preferring the scientific options, though, would just be ambitious, normative naturalism with a new name. The only other option I see for the tolerant naturalist is worse: the hypocritical strain of "tolerance" favored by so many undergraduates-the ones who proclaim moral relativism in the classroom and then vote, march, and generally judge as though some ethical views were better than others after all.

To these explicitly tolerant views I would add the implicitly tolerant group of naturalistic "undefiners"-naturalists who deliberately demur from defining naturalism in an informative way. David Papineau, both in his 1993 book on naturalism and later in his entry on naturalism for the Stanford Encyclopedia of Philosophy, simply begs off of definition. As he put it in the encyclopedia entry:

... this entry will not aim to pin down any more informative definition of "naturalism." It would be fruitless to try to adjudicate some official way of understanding the term. Different contemporary philosophers interpret "naturalism" differently. ${ }^{13}$

Similarly, Maddy says of her brand of naturalism that it "isn't a set of beliefs, a set of propositions to be affirmed; it has no theory ... its contours can't be drawn by outright definition." ${ }^{14}$ Quentin Smith skirts the problem by defining naturalism as that which permits nothing supernatural. ${ }^{15}$ This is unhelpful as a definition until we have a very specific idea of what counts as supernaturalwhich seems to be an equivalent problem. (For example, would nonphysical mental properties be "supernatural" or not?) In his encyclopedia entry, Papineau says he is reluctant to define naturalism because so many want to claim its positive connotations that too few will be happy with any given definition. This strikes me as placing the cart before the horse. Imagine making such a response to the challenge of defining democracy, for example. If despots want to call their envisioned government "democratic" in order to capture its positive connotations, this would make defining the term in a principled way all the more urgent. Naturalistic cannot maintain its positive connotations if any project satisfies it, or if it is totally unclear which do.

To the extent such tolerant naturalisms are unpalatable, that is the extent to which we are committed to the normative aspect of naturalism. Both horns, then, are threatening. 


\section{Naturalism As Literally Self-Explanatory}

What the naturalist would like is an internally consistent but sufficiently normative naturalism: a scientific way to say that science is an importantly better route to knowledge than nonscience. As it happens, I think many philosophers already hold such a view in practice-it just has not been sufficiently articulated yet.

In overview, my solution is a recipe of the following three steps:

1. Construe naturalism as a methodological commitment to science.

2. Construe science as inference to the best explanation.

3. Construe explanation as conceptual unification.

Though each of these steps will have its opponents, they are at least independently plausible and widely accepted. Taken together, they provide a way out of the dilemma naturalists face.

\subsection{STEP One: Naturalism Is Scientism}

My first hypothesis is about the broad nature of naturalism-roughly, that naturalism is a kind of "scientism."

$(\mathrm{N}=\mathrm{S})$

Naturalism is the view that science is the only route to knowledge.

This hypothesis merits three quick disclaimers. First, I use the word scientism somewhat idiosyncratically and anachronistically here, simply as a handy shorthand for $\mathrm{N}=\mathrm{S}$. I do not intend the straw-man connotations scientism carries these days, according to which (for example) science is the only worthwhile human endeavor. $\mathrm{N}=\mathrm{S}$ does not claim science has jurisdiction over art, friendship, or other meaningful but non-knowledge-seeking activities. Second, the claim is not that science is the only route to true beliefs, since of course even astrology can get those sometimes. $\mathrm{N}=\mathrm{S}$ claims rather that science is the only good route to true beliefs-the only one that results in knowledge. Finally, everyday knowledge (such as "Barack Obama is president of the United States in 2014") may seem to make for easy counterexamples. But by science I do not mean something so esoteric as to require a lab, a $\mathrm{PhD}$, and grant funding-discovering everyday facts are still (if done well) investigating the world scientifically. It is just that this level of science is so easy for most of us that we do not even notice it. ${ }^{16}$

If the $\mathrm{N}=\mathrm{S}$ hypothesis is correct-and assuming that we value knowledgewe immediately recapture the normative aspect of naturalism via its exclusionary clause. Of course, this hypothesis does not on its own settle whether naturalism advocates the correct route to that epistemic good; it merely would settle, if correct, why and in what sense naturalism is in the normativity business. Now for escaping the incoherence objection, which requires the other two hypotheses.

\subsection{Step Two: Scientism Is Explanationism}

Next is probably the most controversial of my hypotheses: 
$(\mathrm{S}=\mathrm{E})$

The scientific method is inference to the best explanation.

This is, in effect, a proposal to solve the scientific demarcation problem. Of course, I do not intend in a few short pages to give a full defense of such a sweeping proposal. My goal here is just to give it plausibility and then show how it fits with our common conceptions of naturalism and science.

First, to address briefly a natural objection: $\mathrm{S}=\mathrm{E}$ seems to rule out the purely deductive practice of mathematics as nonscientific, and yet surely mathematics is a source of knowledge. Mathematics is a problem for many a naturalist, but my version of naturalism actually handles this better than most. I cannot explain why, though, until we get to the third hypothesis (on explanation as unification).

The main motivation for $\mathrm{S}=\mathrm{E}$, meanwhile, is basically the Quine-Duhem thesis. In its most radical form, this holds that the theoretical core of any consistent theory is consistent with any body of observations; as Quine put it, "any statement can be held true come what may, if we make drastic enough adjustments elsewhere in the system."17 In light of the Quine-Duhem thesis, the problem of demarcation becomes in effect one of determining when such maneuvers are properly scientific. Given that multiple conflicting theories are each consistent with the data available, this amounts to the need to pick theories on grounds other than mere consistency with the observations. Of course, the goal is to pick the best of these theories capable of explaining the data. What makes one theory better than another is theoretically contentious, of course, though in practice it is often fairly obvious. Traditionally, the supreme theoretical virtue is simplicity; roughly, a theory is better if it can explain more with less. ${ }^{18}$ Whatever might determine the best data-fitting theory, though, to pick it seems basically to do both science and inference to the best explanation (IBE).

As a second plausibility argument for $\mathrm{S}=\mathrm{E}$, consider some clearly nonnaturalistic claim-for example, the claim that the positions of particular stars and planets when we were born significantly influence our romantic lives. Suppose now that, contrary to all reasonable expectations, someone came up with a good explanation for how it is that the stars' positions at our births can so influence us, in a way strikingly close to the way astrology predicts. (It is not hard to concoct some story for how this might happen, and I leave it as an exercise for the reader.) The point is that from the moment such a good explanation appeared, it seems, astrology would become naturalistic. What plausibly makes it clearly nonnaturalistic now is exactly its resistance to good explanation. Astrology is, as it stands, inference to a theory that relies essentially on mystery. It is believed despite putative connections between stars and romance that are utterly baffling even to its strongest proponents.

I think the same is true for immaterial souls, new-age crystals, and the parting of the Red Sea. If we actually had a good explanation for how such things worked, they would integrate into perfectly respectable naturalistic theories. (And, I grimly suspect, the newly explained phenomenon would often then cease to have the popular appeal it once had.) To the extent good explana- 
tions can turn a nonnaturalistic project into a naturalistic one, we have support for the twin theses of $\mathrm{N}=\mathrm{S}$ and $\mathrm{S}=\mathrm{E}$.

\subsection{STEP THREE: EXPLANATIONISM IS UNIFICATIONISM}

So far, though this naturalism is appropriately ambitious, it still looks vulnerable to the incoherence charge. And in fact, on one of the most popular accounts of explanation, this form of naturalism is indeed incoherent. According to the causal account, to explain some fact is (roughly) to show how it came about rather than some contrary fact, and this amounts to detailing its causes. ${ }^{19}$ If this is the right account of explanation, then it seems there can be no explanation in fields such as philosophy or math, since those do not typically advert to causal stories. Thus, by $\mathrm{S}=\mathrm{E}$, philosophy and math would be nonscientific, and so by $\mathrm{N}=\mathrm{S}$ nonnaturalistic.

Another popular approach to explanation, though, does not have this implication.

$(\mathrm{E}=\mathrm{U})$

Explanation is unification.

Again, my goal here is not to defeat all competing accounts of explanation but rather simply to show that $\mathrm{E}=\mathrm{U}$ is independently plausible and that it can solve the dilemma for naturalism.

The picture of explanation here is most familiar from the work of Michael Friedman and Philip Kitcher, ${ }^{20}$ though I am not committed to one particular version of the $\mathrm{E}=\mathrm{U}$ thesis. I need only the basic idea-namely, that explanations are attempts to unify our knowledge by subsuming the explanandum into a wider pattern. To provide an explanation is, in Kitcher's words, to "reduce the number of types of facts we must accept as brute." ${ }^{21}$ That is, to explain is to reduce the totality of unanswered why-questions-ideally by batches (types) - by showing how the answers to some follow from other unexplained phenomena that we already accept. For example, Newton famously answered the question of why planets have the orbits they do by showing how it follows from what we already accept about gravity locally. That answer of course generates its own why-question ("Why does gravity behave that way?"), which might in turn follow from other unexplained phenomena that minimize the totality still more (perhaps, "because 11-dimensional strings behave this way"). The unification at issue is comparable to the "consilience" of William Whewell and E. O. Wilson. ${ }^{22}$

If unification is the correct account of explanation, then there can be explanation in philosophy. Philosophy attempts to systematize our concepts, which seems equivalent to explaining (or sometimes explaining away) our conceptual intuitions with unified theories. Compare John Rawls's celebrated philosophical methodology of "wide reflective equilibrium," ${ }^{23}$ according to which we try to capture as many of the ethical intuitions as we can by a consistent, unifying ethical theory-just as a physicist tries to capture observations with a unifying physical theory. Of course, we may throw out some intuitions as mis- 
taken (ideally in combination with a theory about why we would make such errors), just as scientists can have good motivation to throw out data outliers (again, ideally with explanation for their occurrence). On the view before us, the similarity is more than coincidence; it is exactly the same methodology. Theories in normative ethics explain intuitions such as "it is wrong to torture infants," theories in epistemology explain intuitions such as "beliefs from wishful thinking are unjustified," and theories in metaphysics explain intuitions such as "one thing can cause another." (This last is part of why, by its own lights, the unification account of explanation is superior to the causal one-it is not required to take mysterious causation as primitive.) Furthermore, if $\mathrm{S}=\mathrm{E}$ is correct and inference to the best explanation is indeed definitive of science, then analytic philosophy is literally a scientific enterprise-and so, by $\mathrm{N}=\mathrm{S}$, naturalistic. The subject matter of philosophy is of course different from physics or biology, since philosophy seeks to unify conceptual intuitions rather than empirical observations, ${ }^{24}$ but the methodology is the same, and it is the methodology that is definitive of science. It is in this way, I think, that philosophy is "continuous with science," as Quine famously put it. ${ }^{25}$

And with $\mathrm{E}=\mathrm{U}$, we can see how this naturalism handles mathematics better than most. As Kitcher likes to emphasize, when we take explanation as unification, we can make sense of explanations in mathematics too. ${ }^{26}$ Proofs plausibly reduce unanswered why-questions by showing how theorems depend on axioms, and we accept the axioms in part because they are so explanatory (in the unification sense) of mathematical truths. In effect mathematics, too, can be a form of IBE-and so scientific, and so naturalistic.

\subsection{A Coherent Naturalism}

Now we are in a position to solve the problem of internal coherence by giving a positive answer to the question: Could naturalism itself be naturalistic? Note the word could is important, since we cannot hope to guarantee that someone's naturalism will be naturalistic; after all, one could come to this methodological commitment in a methodologically odious way. For internal consistency, it is enough to show it is possible for ambitious naturalism to be held on naturalistic grounds.

By $\mathrm{N}=\mathrm{S}$, the question of whether ambitious naturalism can itself be naturalistic reduces to this question: Could "science is the only route to knowledge" itself be a scientific claim? Of course, whether science is the only route to knowledge is a philosophical (epistemological) question. But that does not rule it out as a scientific question, on the broad construal here. In fact, by $\mathrm{S}=\mathrm{E}$, the second question further reduces to this question: Could inference to "the best explanation is the only route to knowledge" itself be a claim resulting from inference to the best explanation?

The question of whether IBE is the only route to knowledge is clearly an epistemological one. But as suggested earlier, one way to approach epistemology is by finding the best (simplest, etc.) unification of our epistemic intuitions. That is, by $\mathrm{E}=\mathrm{U}$, you can do epistemology by IBE. In particular, "IBE is the only route to knowledge" is just the kind of thing that an epistemologist might posit 
as the best unification of our epistemic concepts. Thus the answer to the third question is "yes," and so the answer to the first question is also "yes." Naturalism can indeed be naturalistic, because naturalism can be literally self-explanatory.

Here, then, is the view in sound-bite form:

$(\mathrm{N}=\mathrm{U})$

Naturalism is scientism is explanationism is unificationism.

I have argued that $\mathrm{N}=\mathrm{U}$ is both ambitiously normative and internally coherent. It also makes sense of philosophy as continuous with the sciences, and makes for a plausible demarcation of the scientific and naturalistic.

Of course, it has some problems. But I do not think they are as bad as they may seem.

\section{Too Broad a Naturalism?}

To gain this solution, we had to broaden significantly what many would intuitively count as "scientific" or "naturalistic." This may seem like too high a price to pay. When naturalism is understood so broadly, it can look trivial—or at least too ecumenical to rule out its intended targets. Almeder (1998) and Moser and Yandell (2000) both press specific versions of this objection against a view like mine. Rather than address their objections directly, in the interest of space I will consider what I think is the most general and forceful illustration of the objection that, in Moser and Yandell's words, liberalizing naturalism this far robs it of its "epistemological teeth."

\subsection{Naturalistic Theism}

The problem, in a nutshell, is this: $\mathrm{N}=\mathrm{U}$ is so liberal that it does not even rule out theism — at least, not as a direct consequence of the view. To see this, consider this quotation from Richard Swinburne, picked to represent his 1996 book on its back cover:

Not everything will have an explanation. But the whole progress of science and all other intellectual enquiry demands that we postulate the smallest number of brute facts. If we can explain the many bits of the universe by one simple being which keeps them in existence, we should do so-even if inevitably we cannot explain the existence of that simple being. ${ }^{27}$

Here Swinburne is—about as explicitly as one could hope-using a methodology that seeks conceptual unification, and thus a view $\mathrm{N}=\mathrm{U}$ would countenance as purely naturalistic. This is surely an odd consequence of my view. If a version of naturalism admits avowed theists, then it would be understandable to say that version has no epistemological teeth.

Note, though, that this problem will burden any methodological naturalism. Like many naturalists, I am inclined to think that Swinburne is using the IBE method incorrectly (though I would not pretend it is trivial to demonstrate as much). Whether Swinburne's own use is good or not, at any rate, surely it is possible to use IBE badly. If used badly enough, presumably, IBE could support 
just about any claim - thus making any claim the potential result of naturalistic methodology. But this fact is hardly unique to IBE; it seems to hold for any (fallible) method. Whatever method might be proposed as defining methodological naturalism, someone could abuse that same method badly enough to arrive "naturalistically" at belief in pixies, let alone God.

So this is an issue for any methodological naturalism. Why, then, does it strike us as so counterintuitive? I think the oddity of this result comes from confusing methodological naturalism with ontological naturalism (or, as it is sometimes called, metaphysical naturalism). The problem sometimes called "Hempel's dilemma" convinces me that ontological naturalism is badly problematic. Daniel Stoljar puts the dilemma succinctly in discussing the closely related problem of defining physicalism:

If physicalism is defined via reference to contemporary physics, then it is false-after all, who thinks that contemporary physics is complete?-but if physicalism is defined via reference to a future or ideal physics, then it is trivial-after all, who can predict what a future physics contains? ${ }^{28}$

Given this problem, the best I can make of ontological naturalism is something like this: What exists is only what would be endorsed by the ideal and thorough application of the naturalistic method.

The advantage of this kind of naturalism is that it licenses speaking of things as naturalistic or not, independent of our current application of method. Those attempting to apply the naturalistic method might now disagree on whether there are superstrings, unicorns, or gods, but by the definition above each of those is now such that it is either ontologically naturalistic or it is not.

The disadvantage of this kind of naturalism - as the Stoljar quotation suggests-is that our epistemic access to it is shaky at best. On this reading, to say "a theory that contains God is not naturalistic" does not mean that no one could come to believe in such a theory by naturalistic methods- that would be too uncharitable a reading of the claim, since surely someone could. It means instead that no one could believe in God by correct application of naturalistic method. This has more of a chance of being true, but it is certainly a bold claim. Thus to say an entity or theory is not naturalistic is best read as saying it is not ontologically naturalistic, and to say that is to write a promissory note to the effect that the theory or entity will not turn out to be properly explanatory. Such a promissory note needs to be cashed out in terms of ground-level debates about explanatory power. That is what I mean when I say that atheism is not a "direct consequence" of my view—nor of any other methodological naturalism. Swinburne does what many call natural theology—where "natural" is meant, I think, in just the sense I mean it here.

In summary, methodological naturalism rules out only other methods, not particular theories. I actually take this as an advantage for my characterization of science and naturalism. We do not want to approach the demarcation of the naturalistic by simply marking which theories and entities are on which sides, as though we introspected a Platonic list. That would make naturalism into an empty, rhetorical way of stating which projects particular people like and do not like, without principled reasons. Such a list would have feeble normative 
bite. Instead we want a theoretically motivated standard of methodology—one that any project could in principle meet. Compare this challenge from Alston:

... what if physics should begin taking into account psychic forces or the élan vital, or other factors we now consider to be clearly non-physical. Would we be prepared to recognize them as physical properties in that case? ${ }^{29}$

The naturalist's answer to this challenge should be "yes." Assuming physics begins taking such things into account because they need them for the best explanation of observed phenomena, then they should be recognized as natural, physical properties. (At least, they should be recognized as natural properties; my account allows for room between the "physical" and the "natural," à la David Chalmers's view of qualia. ${ }^{30}$ ) Science has adduced unusual basic properties or entities for explanatory purposes many times before; consider Newton's universal gravitation, which was considered too occult for science until its explanatory power became persuasive. As with the earlier thought experiment of naturalistic astrology, we should stay open to the possibility that science could potentially go any number of surprising ways-even toward endorsing nonphysical qualia or the élan vital—and still be science.

\subsection{NATURALISM's Bite}

That is all fine, but we might still be left wondering where $\mathrm{N}=\mathrm{U}$ has any epistemic bite. Well, one reassuring place it has bite is the wider populace. Strikingly, many non-philosophers-even quite intelligent ones—will cheerfully say that they believe some view because it is mysterious, or because they hope it is true, or for reasons totally other than the explanatory. My version of naturalism clearly rules out such views. To rule out such unreflective views may be a trivial philosophical triumph, but it would be a notable political one if naturalism gained wider audience.

In philosophy too, though, $\mathrm{N}=\mathrm{U}$ has important traction. In fact, if we take the Stanford Encyclopedia of Philosophy to be a decent guide to the general philosophical zeitgeist, then it seems current epistemology of religion turns entirely on methodological naturalism. The article on religious epistemology summarizes the debate as one about "whether evidentialism applies to the belief-component of religious faith, or whether we should instead adopt a more permissive epistemology." 11 These epistemologies that are more "permissive" than evidentialism, I believe, are just what is at stake in the debate over methodological naturalism. And $\mathrm{N}=\mathrm{U}$ is just a species of evidentialism, with a more specified notion of both the "evidential" and of the "ism." Antinaturalists who are tempted to say that I rescue the coherence of naturalism only by setting the bar too low should consider whether they are ready to sign on as card-carrying, IBE-only evidentialists. If they are, then I admit my view must have less bite than I thought—but I would be delighted to discover as much, since it would mean that issues over philosophical methodology are largely settled, and that is no trivial feat. We could then get to the details of the disagreements. If there is resistance to evidentialism, though-as vigorous debate over religious epistemology would suggest—-then my view must not set the bar too low to be 
exclusionary. Alvin Plantinga, for example, explicitly rejects Swinburne-style explanationist approaches to theism; he worries that it is mere "God-of-thegaps" theology, to be constantly threatened by the advances of science. Instead, he insists knowledge of God must come from a source other than IBE:

... the thought that there is such a person as God is not, according to Christian theism, a hypothesis postulated to explain something or other, nor is the main reason for believing that there is such a person as God the fact that there are phenomena that elude the best efforts of current science. Rather, our knowledge of God comes by way of general revelation, which involves something like Aquinas's general knowledge of God or Calvin's sensus divinitatis, and also (and more importantly) by way of God's special revelation, in the Scriptures and through the church, of his plan for dealing with our fall into $\sin ^{32}$

Such "more permissive epistemologies" are the true barrier to the naturalist's aims, in my view. Philosophy of religion is not the only subdiscipline in which they appear-though it may be the only one in which it is sometimes explicitly endorsed. For this reason, any particular accusation of antinaturalism in any other sub-discipline will be fairly contentious.

\section{The Dialectic}

For these reasons, then, I think $\mathrm{N}=\mathrm{U}$ is a naturalism that captures many key desiderata:

- It is normative.

- It is internally coherent.

- It characterizes naturalism in a principled, rather than ad hoc, way.

- It makes philosophy continuous with science.

- It is properly exclusionary-it has reasonable epistemic bite.

Aside from these advantages, my proposal is conservative in the sense that its methodology is not far from what most analytic philosophers take to be standard philosophical practice, implicitly if not explicitly.

I conclude with a note about the current dialectic. Though $\mathrm{N}=\mathrm{U}$ sidesteps a serious potential incoherence for naturalism, I am not so naive as to think that is any mark in favor of the view. Self-endorsement is cheap; a divine revelation can confirm that divine revelation is a route to knowledge, and a consultation of the stars can confirm that astrology is a route to knowledge. It is a good result for naturalism that it can bootstrap, but a methodological skeptic can reasonably ask why we should start by tugging that bootstrap rather than some other, nonnaturalistic one. It is a familiar worry that there can be no good answer to this question, because any explicit justification for a choice of method must arise from a belief-forming mechanism that is at that point suspect.

I share pessimism about a general solution to this problem; it may just be one with which we have to live. The advocate of IBE has a pragmatic leg up here, however, because as a matter of (empirical) fact, humans capable of even asking the kind of questions relevant here cannot help using IBE in at least some cases. The most dedicated astrologist you're likely to find will still look at 
wet sidewalks and conclude, without ever consulting the stars, that it must have rained. They will encounter a cliff and conclude, again through unreflective IBE, that stepping over the edge is unlikely to promote health-and so on for the vast majority of their beliefs. If IBE is indeed this pervasive, then it will be available to provide a common ground between those disputing methods. The issue over permissive epistemologies becomes whether we should use IBE plus some other method(s), or IBE alone; rejecting IBE outright is not typically on the table. Given this, the disputants can discuss on explanatory grounds the merits of the other methods at issue. Here, of course, the claim that IBE is the only proper method will have a strong presumption, since its claim that there is at root only one method for forming good beliefs is more simple and unificatory.

Such disputes-taking IBE for granted in order to discuss the worth of non-IBE methods-are not merely exercises of imagination. They happen every time philosophers disagree about whether there are nonnaturalistic routes to knowledge. As philosophers, they take on board philosophical methodology (plausibly, IBE methodology) to ask whether some extra methodology might be legitimate. If a philosopher gave no reasons to treat divine revelation as a source of knowledge other than by appealing to its legitimacy as a revealed truth, she or he would at that point have given up the philosophy game. Again, though, this is only a pragmatic point in favor of IBE; it is epistemically consistent to reject IBE outright and trust only the deliverances of divine revelation, or astrology, or some other non-naturalistic but self-endorsing method. Naturalists such as me are likely to give such methods a dismal chance of success, but that is just because we are already committed to naturalism.

\section{ACKNOWLEDGMENTS}

Thanks to Marc Alspector-Kelly, William Bristow, Robert Gressis, John Keller, Blain Neufeld, and William Wainwright.

\section{NOTES}

1. The PhilPapers survey gives a figure of 49.8 percent accepting or leaning toward naturalism and 25.8 percent accepting or leaning toward non-naturalism, out of 931 target faculty. See http://philpapers.org/surveys/results.pl.

2. Paul K. Moser and David Yandell, "Farewell to Philosophical Naturalism," in Naturalism: A Critical Analysis, eds. William Lane Craig and J. P. Moreland (New York, Routledge, 2000), 10-11. For "ambitious naturalism" they substituted what they called "Core Scientism"- the twin claims of "Core ontological naturalism" (that, roughly, the only objects that exist are those countenanced by science) and "Core methodological naturalism" (that, roughly, the only route to knowledge is through scientific methods).

3. William P. Alston. 2002. "What Is Naturalism, That We Should Be Mindful of It?" http:// www.leaderu.com/aip/docs/alston-naturalism.html.

4. Robert Almeder. Harmless Naturalism: The Limits of Science and the Nature of Philosophy (Chicago: Open Court, 1998), 64.

5. Harvey Siegel, "Empirical Psychology, Naturalized Epistemology, and First Philosophy," Philosophy of Science 51 (1984): 667-76; Laurence BonJour, "Against Naturalized Epistemology," Midwest Studies in Philosophy 19 (October 1994): 22-23; Nicholas Rescher, "The Editor's Page," American Philosophical Quarterly 29 no. 3 (1992): 301-2; Alex Rosenberg. "A Field Guide to Recent 
Species of Naturalism," British Journal for the Philosophy of Science 47 (1996): 1-29; Paul Sagal, "Naturalized Epistemology and the Harakiri of Philosophy," in Naturalistic Epistemology: A Symposium of Two Decades, eds. Abner Shimony and Debra Nails (New York: Springer, 1987), 321-33.

6. Robert Almeder, Harmless Naturalism: The Limits of Science and the Nature of Philosophy (Chicago: Open Court, 1998), 198 (footnote 66) and 36.

7. Moser and Yandell, "Farewell."

8. Marc Alspector-Kelly. 2006. "How to Be a Naturalist."

9. Robert Almeder. Harmless Naturalism: The Limits of Science and the Nature of Philosophy (Chicago: Open Court, 1998), 197 (footnote 65).

10. Alspector-Kelly, "How to Be a Naturalist."

11. Penelope Maddy. Second Philosophy: A Naturalistic Method (Oxford: Oxford University Press, 2007), 85.

12. Robert Almeder. Harmless Naturalism: The Limits of Science and the Nature of Philosophy (Chicago: Open Court, 1998), 143. I should note here that Almeder's version of naturalism can claim that some questions are purely scientific. But in giving up ambitious naturalism-which he calls the "replacement thesis"-Almeder's version countenances any claim for which there is some possible set of circumstances that would tell for or against the claim, whether or not anyone can even state what these circumstances would be (p. 166). Thus programs such as astrology-not to mention intelligent design-are straightforwardly naturalistic, on his view.

13. David Papineau. Philosophical Naturalism (Cambridge, Mass: Blackwell Publishing, 1993). "Naturalism," in The Stanford Encyclopedia of Philosophy, ed. Edward N. Zalta (Stanford, CA: The Metaphysics Research Lab, 2007).

14. Penelope Maddy. Second Philosophy: A Naturalistic Method (Oxford: Oxford University Press, 2007), 2.

15. Quentin Smith. "The Metaphilosophy of Naturalism.” Philo 4, no. 2 (2001).

16. C. S. Peirce concurs: Looking out my window this lovely spring morning I see an azalea in full bloom. No, no! I do not see that; though that is the only way I can describe what I see. That is a proposition, a sentence, a fact; but what I perceive is not proposition, sentence, fact, but only an image, which I make intelligible in part by means of a statement of fact. This statement is abstract; but what I see is concrete. I perform an abduction when I so much as express in a sentence anything I see. The truth is that the whole fabric of our knowledge is one matted felt of pure hypothesis confirmed and refined by induction. Not the smallest advance can be made in knowledge beyond the stage of vacant staring, without making an abduction at every step. (Charles Saunders Pierce, "The Proper Treatment of Hypotheses; A Preliminary Chapter, Toward an Examination of Hume's Argument Against Miracles, in Its Logic and in Its History," 1901.)

17. W. V. O. Quine. "Two Dogmas of Empiricism," in From a Logical Point of View (Cambridge, Mass: Harvard University Press, 1951), 43.

18. Other notable candidates for theoretical virtues include conservativeness (minimizes change from past theories) and fecundity (suggestive of future work). See, for example, the seminal Gilbert Harman, "The Inference to the Best Explanation," The Philosophical Review 74, no. 1 (1965): 88-95 and Paul Thagard, "The Best Explanation: Criteria for Theory Choice," Journal of Philosophy 75, no. 2 (1978): 76-92.

19. David Lewis. "Causal Explanation," in Philosophical Papers 2 (1986): 214-40; Wesley Salmon. Causality and Explanation (Oxford: Oxford University Press, 1998).

20. Michael Friedman. "Explanation and Scientific Understanding." Journal of Philosophy 71 no. 1 (1974): 5-19; Philip Kitcher. "Explanatory Unification." Philosophy of Science 48 no. 4 (1981): 507-31. 529.

21. Philip Kitcher. "Explanatory Unification.” Philosophy of Science 48 no. 4 (1981): 507-31,

22. William Whewell. Novum Organon Renovatum: Being the Second Part of the Philosophy of the Inductive Sciences. 2007 edition (Whitefish, Mont: Kessinger Publishing, LLC, 1858); Edward O. Wilson. Consilience (New York: Alfred A. Knopf, 1998).

23. John Rawls. A Theory of Justice. 1995 edition (Cambridge, Mass: Harvard University Press, 1971); Norman Daniels. "Wide Reflective Equilibrium and Theory Acceptance in Ethics," Journal of Philosophy 76 no. 5 (1979): 256-82.

24. Or you might rather say: their empirical observations are conceptual intuitions.

25. W. V. O. Quine. "Natural Kinds," in Ontological Relativity and Other Essays (New York: Columbia University Press, 1996), 126. 1985).

26. Philip Kitcher, The Nature of Mathematical Knowledge (Oxford: Oxford University Press,

27. Richard Swinburne, Is There a God? (Oxford: Oxford University Press, 1996), 49. Robert 
Gressis was the first to point out to me that Swinburne would count as a naturalist on my view.

28. Daniel Stoljar, "Physicalism" in The Stanford Encyclopedia of Philosophy, ed. Edward N. Zalta (MacMillan Reference USA: Stanford, Calif, Fall 2009): Online; last accessed November 12, 2009, from http://plato.stanford.edu/archives/fall2009/entries/physicalism/; The Metaphysics Research Lab.

29. William P. Alston. 2002. "What Is Naturalism, That We Should Be Mindful of It?" Available at http://www.leaderu.com/aip/docs/alston-naturalism.html.

30. According to Chalmers's "naturalistic dualism," qualia are nonphysical but natural. They are not physical because (he argues) they are not a matter of structure and function, which he takes to be definitive of the physical. He insists they are natural, though-basically, because they are fundamental properties needed to explain experience. As he puts it, "to embrace dualism is not necessarily to embrace mystery"; instead, he avows a "commitment to natural explanation" (David J. Chalmers, The Conscious Mind [Oxford: Oxford University Press, 1996], 128). This notion of the antinatural as the mysterious I take to sit well with my own proposal that the antinatural is what is believed despite resisting explanation.

31. Peter Forrest, "The Epistemology of Religion," in The Stanford Encyclopedia of Philosophy, ed. Edward N. Zalta (MacMillan Reference USA: Stanford, Calif, Fall 2009): Online; last accessed November 13, 2009, from http://plato.stanford.edu/archives/sum2009/entries/religion-epistemology/; The Metaphysics Research Lab.

32. Alvin Plantinga, "Methodological Naturalism? Part 2," Origins E D Design 18, no. 2 (1997). Online; last accessed November 12, 2009 from http://www.arn.org/docs/odesign/od182/methnat $182 . h$ tm.

\section{REFERENCES}

Almeder, Robert. 1998. Harmless Naturalism: The Limits of Science and the Nature of Philosophy. Chicago: Open Court.

Chalmers, David J. 1996. The Conscious Mind. Oxford: Oxford University Press.

Harman, Gilbert. 1965. "The Inference to the Best Explanation." The Philosophical Review 74 (1): $88-95$.

Moser, Paul K., and David Yandell. 2000. "Farewell to Philosophical Naturalism." In Naturalism: A Critical Analysis, edited by William Lane Craig and J. P. Moreland. New York: Routledge, 3-23.

Peirce, Charles Sanders. 1901. "The Proper Treatment of Hypotheses: A Preliminary Chapter, Toward an Examination of Hume's Argument Against Miracles, in Its Logic and in Its History." Available online at http://www.unav.es/gep/MS692.pdf.

Thagard, Paul. 1978. "The Best Explanation: Criteria for Theory Choice." Journal of Philosophy 75 (2): 76-92. 